Modelling Learners and Learning in Science Education 

Keith S. Taber

\section{Modelling Learners and Learning in Science Education}

Developing Representations of Concepts, Conceptual Structure and Conceptual Change to Inform Teaching and Research 
Keith S. Taber

Faculty of Education

University of Cambridge

Cambridge, UK

ISBN 978-94-007-7647-0

ISBN 978-94-007-7648-7 (eBook)

DOI 10.1007/978-94-007-7648-7

Springer Dordrecht Heidelberg New York London

\section{Library of Congress Control Number: 2013956003}

(C) Springer Science+Business Media Dordrecht 2013

This work is subject to copyright. All rights are reserved by the Publisher, whether the whole or part of the material is concerned, specifically the rights of translation, reprinting, reuse of illustrations, recitation, broadcasting, reproduction on microfilms or in any other physical way, and transmission or information storage and retrieval, electronic adaptation, computer software, or by similar or dissimilar methodology now known or hereafter developed. Exempted from this legal reservation are brief excerpts in connection with reviews or scholarly analysis or material supplied specifically for the purpose of being entered and executed on a computer system, for exclusive use by the purchaser of the work. Duplication of this publication or parts thereof is permitted only under the provisions of the Copyright Law of the Publisher's location, in its current version, and permission for use must always be obtained from Springer. Permissions for use may be obtained through RightsLink at the Copyright Clearance Center. Violations are liable to prosecution under the respective Copyright Law.

The use of general descriptive names, registered names, trademarks, service marks, etc. in this publication does not imply, even in the absence of a specific statement, that such names are exempt from the relevant protective laws and regulations and therefore free for general use.

While the advice and information in this book are believed to be true and accurate at the date of publication, neither the authors nor the editors nor the publisher can accept any legal responsibility for any errors or omissions that may be made. The publisher makes no warranty, express or implied, with respect to the material contained herein.

Printed on acid-free paper

Springer is part of Springer Science+Business Media (www.springer.com) 
Essentially, all models are wrong, but some are useful.

(Box \& Draper, 1987, p. 424) 



\section{Preamble}

Modelling is widely recognised to be important in both the doing of science and increasingly - in the teaching of science. Modelling is equally important in research in science education as it allows us to develop ways of thinking about the nature and structure of complex phenomena and, in particular, to devise simplifications suitable for formal testing. This is especially important in an area like learning. Learning is an absolutely fundamental concern in education (science education or otherwise), and the term refers to a complex set of processes that are not fully understood. Our research in science education often relies on assumptions about the nature of learning and learners, and research to better understand learning in science is a core area of activity. Research in these areas uses and develops constructs, representations and models that are either assumed or proposed to in some sense reflect the 'real' nature of learning. Yet the central role of modelling in research into learning in science has not always been as clearly acknowledged as - for example - the role of modelling in the teaching and learning of the subject. In this book it is suggested that this is problematic as often researchers write (and so perhaps think) as though learning and associated notions such as understanding, thinking and knowing are not problematic. Research papers (as will be illustrated in Chap. 1) commonly report research findings in terms of student knowledge, or understanding, as though the terms are well understood and unambiguous and the notions behind them are unproblematic. Yet, as will be demonstrated here, this is hardly the case.

There is a problem, then, that because notions such as learning and knowing are so familiar from everyday use, researchers often fail to treat them as technical constructs when reporting the outcome of science education research. In some cases, this lack of sophistication undermines the value of the research to the community, as results are presented in terms that treat complex phenomena as though we all understand and agree about their nature. Yet, as this book shows, this is not a warranted assumption.

This book then explores the role of modelling in research exploring learning in science. The fundamental assumption of the book is that research into learning in science necessarily involves making knowledge claims based upon building and 
representing models. Reports in research papers giving accounts of student knowledge, and/or conceptual change, rely upon the models researchers adopt or develop when interpreting their data. It follows that the modelling processes and the nature of the models produced need to be understood by those who read the research reports if the knowledge claims made in research are to be correctly understood and appropriately judged.

In this volume I offer an account of the modelling processes involved in research into student understanding and learning in science. I argue the case for the importance of acknowledging the modelling processes necessarily underpinning any account of student thinking, knowledge or learning. The book reviews the current state of knowledge in science education in relation to the modelling of scientific thinking, understanding and learning in science.

\section{A Note on Teachers as Knowers and Learners}

Much work in science education focuses on the ideas of learners in formal education - school pupils or other students. In general I have written the book referring to learners and largely have such students in mind. However, the book is equally relevant for research into informal learning (e.g. adult museum visitors who would not consider themselves learners) and into teachers - who of course continue to learn about both the subjects they teach and about professional matters such as pedagogy. In recent years there has been a significant literature looking at such matters as science teachers' beliefs about, for example, the nature of science or constructivist pedagogy. Researchers exploring these areas are subject to the same methodological problems and questions regarding the assumptions behind their research as those exploring 8-year-old children's ideas about the shape of the earth or postgraduate students' notions of types of chemical bond. The type of modelling processes inherent in research is the same in all these cases.

Moreover, although the book is largely framed in terms of formal research as reported in journals and other scholarly works, the core argument here is equally important to teachers going about their work in school or college classrooms. Teachers are not usually developing formal models of their students' learning to present in research papers. However, the process of teaching science involves designing instruction that takes into account a learner's current knowledge and understanding. Teaching is a highly interactive process where the teacher seeks to facilitate learners' sense making to shift current knowledge and understanding towards what the curriculum sets out as target scientific knowledge and understanding. That requires a good appreciation of what students already know, where they may have alternative conceptions and how well they understand key concepts.

The effective science teacher is therefore constantly seeking to update their own understanding of the current states of their students' learning. That is, science teaching depends upon an ongoing, informal process of modelling the mental states of learners. Teachers do this by constantly collecting data (by asking questions, by 
reviewing students' work) and analysing it to inform the next steps of the teaching process. In effect all science teachers are involved in a process of continuous action research to inform and improve their teaching, based upon developing models of the mental states of their learners. Action research is primarily context-directed research to inform practice locally rather than the theory-directed research of academic researchers that is intended to have relevance beyond specific research sites and which is formally reported in publications. The models generated by teachers in their day-to-day work will therefore not be subjected to the scrutiny of others in the same way as the academic research discussed in this volume. Yet teachers, often even more so than researchers, tend to take for granted notions of knowledge, understanding, learning, etc., and, just as researchers, they can benefit from problematising these issues and reflecting on just how they understand - and so implicitly model these concepts that are so central to their day-to-day work. 



\section{Acknowledgements}

The author would like to thank John Gilbert for originally encouraging the preparation of this volume and Bernadette Ohmer - my publishing editor at Springer - for her patience and support during the writing of this book. I would also like to acknowledge and thank the anonymous referee who offered positive feedback with helpful suggestions on a full draft of the manuscript. As always, it is useful to have a reader's perspective on what one writes - especially for a book that emphasises how imperfect public representations of our thinking (such as the text of this book) are interpreted in other minds that impose their own sense on them.

This book is located in science education but draws strongly on cognitive science and psychological research and scholarship. Whilst reasonable attempts to offer appropriate citations to previous work have been made in accordance with academic conventions, I am very aware that the message of Chap. 5 is that human memory is not primarily a faculty for providing accurate records of past experience, but rather has evolved to support future action in the world. Memories are often hybrids of our past interpretations of events, patched up with what seems so feasible (based on our general knowledge of the world) that we can no longer see the seams between what we actually experienced and what it now just seems most likely we experienced.

Introspection suggests that my own memory certainly is quite good at recalling 'gist', but often poor at reporting specifics of past experience. My suspicion (or perhaps my hope) is that such a memory supports a strongly synthetic way of thinking that is able to make connections and recognise general patterns rather than focusing on the minutiae of specific details. That does not excuse bad scholarship, but I am aware that I inevitably own an enormous debt to the authors of many things I have read over the years that are not cited here as well as to colleagues and students for things I have heard in presentations and in conversations in both formal and informal contexts. I have sought to acknowledge those key sources I am aware have informed my thinking, and I would here like to acknowledge that I am aware that I am surely drawing on many other sources that I either no longer specifically recall or have simply not recognised as influences in writing this book. 
I suspect there may even be some good ideas in here that I present as if original, but which have worked their way into my consciousness so slowly that I was unaware that their original inspiration was something I had long ago read or heard. I take some comfort in knowing that if this is indeed so, my failure is probably not so unusual, as is indicated by occasional high-profile examples such as when George Harrison was sued for a great deal of money for not acknowledging a highly popular song was very similar to an earlier hit written by someone else. At least working in the academic world, rather than 'the material world', such unconscious plagiarism is unlikely to lead to claims for vast amounts of unpaid royalties.

My only defence is that the model of cognition offered in this book suggests that my failings here are due to the effective way in which the human brain interprets and integrates experience to provide a viable knowledge base for ongoing effective action in the world. Human memories, like the models mooted in this book, need to be understood not as being true replicas of aspects of the world, but rather as useful thinking tools that are fit for purpose. Both should be judged by how they help us move forward, and I very much hope this book will provide useful ways of thinking for those working in science education and looking to develop pedagogy or advance research programmes.

Finally, I would like to dedicate this volume, with love, to my wife Philippa, who has suffered significant health issues during the preparation of the book. At times my academic work has had to be given a low priority in our lives, and the writing has been disrupted. Despite considerable challenges, however, Philippa has understood my drive to push forward in my work and has offered her love and support to help me balance family and work responsibilities. Completing this manuscript despite major distractions is an achievement of 'team Taber'.

Any errors, or other failings, are of course the author's own. 


\section{Contents}

\section{Part I Introduction}

1 The Centrality of Models for Knowledge Claims in Science Education .......................................................................... 3

Some Examples of Knowledge Claims Made in Studies....................... 4

Knowledge Claims in Research ............................................................ 5

Locating This Work Within a Research Programme ............................... 6

The Constructivist Research Programme...................................... 6

Progressing the Research Programme............................................... 8

Assumptions Informing the Research Process

May Not Be Explicit .......................................................................... 9

The Centrality of Models in Research .............................................. 12

Shared Community Commitments ................................................ 14

Being Explicit About the Frameworks Underpinning

Educational Research ...................................................................... 15

Claims About Technical and Common-Sense Notions ...................... 16

The Value of Clarity in Language .................................................... 18

Making the Research Process Explicit.......................................... 18

An Example of a Study Reporting Student Misconceptions............... 19

Knowledge Claims Need to Be Understood as Being About Models ...... 22

\section{Part II Modelling Mental Processes in the Science Learner}

2 Introduction to Part II: The Mental Register .................................. 27

The Problem of Natural Language in Technical Studies ....................... 29

Folk Psychology as a Lifeworld Structure ............................................... 31

Mental Life........................................................................... 32

3 Modelling Mental Activity ............................................................. 35

Everyday Notions Related to Conceptual Learning......................... 35

The Mind ........................................................................................... 37 
Mind and Matter........................................................................ 38

Thought as an Epiphenomenon......................................................... 39

The Problem with a Dualist Model of Mind ...................................... 41

Consciousness as an Emergent Property of Processing ......................... 42

Different Levels of Analysis of Cognition ............................................ 43

Neuroscience ........................................................................... 43

Locating Consciousness in the Brain .......................................... 44

Systems Analysis ...................................................................... 45

Mental Activity ........................................................................ 46

Mental Apparatus and Mental Resources ........................................ 46

Explanatory Power of the Three Levels of Description .................... 46

Consequences for Science Education ....................................................... 48

Representing the Learner .............................................................. 48

Principles Informing the Account in This Book .................................. 49

4 The Learner's Ideas ....................................................................... 51

The Idea of Ideas.............................................................................. 51

The Source of Thoughts and Ideas .............................................. 52

Sensation and Perceiving the World ...................................................... 52

The Apparatus of Sensation ............................................................ 52

Representations May Seem Realistic ............................................... 55

Sensory Representation Involves a Coding System ......................... 56

Sensory Information Is Selectively Filtered Before

Reaching Awareness .................................................................... 57

Executive and Non-executive Processing Modules........................... 58

Sensory Information Is Patched-Up Before Being

Perception Is the Outcome of Active Processing

of Sensory Information .................................................................. 61

Perception May Involve Over-Interpretation .................................... 62

Innate Bias in Perception ........................................................... 63

Learnt Bias in Perception .................................................................. 64

Perceiving Communication from Others......................................... 65

Paying Attention: Distinguishing Subliminal

and Preconscious Processing .......................................................... 65

Recalling Experiences....................................................................... 68

Imagining Possibilities ..................................................................... 68

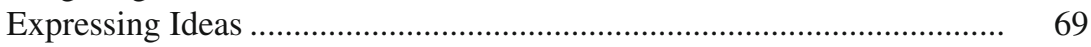

Representing Ideas ....................................................................... 69

Accessing Another's Ideas .................................................................... 74

Research to Investigate Learners' Ideas in Science ................................ 75

Modelling Student Ideas .............................................................. 76

5 The Learner's Memory................................................................... 79

Memory 'Contents' ..................................................................... 79

Memory as a Source of Our Ideas.......................................................... 80

The Physical, Functional and Mental Aspects of Memory...................... 80 
The Nature of the Learner's Memory Store ........................................... 82

Long-Term Memory .......................................................................... 83

The Cortical Basis of Memory ............................................................ 84

Active Memory and Focus of Representation ................................. 87

Memory Is Reconstructive ............................................................ 87

False Memories ........................................................................... 90

False Memories in Science Education Research:

An Example from the Literature ................................................... 91

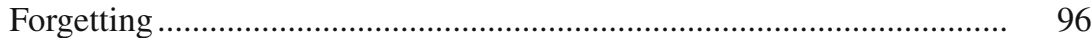

Significance of Forgetting for Science Education............................ 97

A Case of Learning and Forgetting in Science Education ................. 97

Regression in Learning ....................................................................... 99

A Tendency to Integration.......................................................... 101

Memory Consolidation............................................................. 102

Memory Enhancement? .............................................................. 103

Working Memory ............................................................................. 104

Executive Function of WM ........................................................... 105

Models of WM ................................................................................ 106

The Role of WM in the Cognitive System..................................... 108

WM Capacity ...................................................................... 108

Visual Memory and Eidetic Imagery ......................................... 110

Educational Significance of WM Capacity .................................... 110

Chunking .............................................................................. 111

Memory Techniques ............................................................... 114

The Mnemonic .............................................................................. 115

Overview: Modelling Memory........................................................ 116

6 The Learner's Understanding ......................................................... 119

The Meanings of Understanding ..................................................... 120

Understanding the Meanings of Others............................................ 120

Making Sense of the World .......................................................... 120

Two Perspectives on Understanding .................................................. 121

Normative and Idiographic Approaches to Exploring

Understanding ......................................................................... 122

Testing Student Understanding .................................................... 122

Exploring Student Understanding ................................................ 123

Two Approaches to Research ........................................................... 124

Testing Student Understanding: Challenges
of the Normative-Positivistic Approach............................................. 124

Operationalising Target Understanding ........................................ 125

Developing Test Items ................................................................ 125

The Messy Nature of Student Understanding ...................................... 126

An Example of Manifold Understanding of a Science

Topic: Student Understanding of Ionic Bonding.............................. 128

Different Ways of Understanding ..................................................... 132 
Meta-understanding and Multiple Understanding ........................ 133

Understanding Distinguished from Beliefs ....................................... 134

Alternative Interpretations of Perceived Manifold Conceptions......... 135

Describing Student Understanding: Challenges

of the Idiographic Approach ............................................................ 136

The Researcher's Dilemma ......................................................... 137

Comprehending Language ............................................................ 138

7 The Learner's Thinking ............................................................ 141

A Study on 'Scientists and Scientific Thinking' .............................. 141

Establishing a Meaning for 'Thinking' ................................................. 143

Thinking and Processing .............................................................. 144

The Significance of Preconscious Processing ................................. 147

Thinking as an Inclusive Term ......................................................... 148

Forms of Thinking Valued in Science Education .................................. 149

Scientific Thinking ..................................................................... 149

Science-as-Logic: Logical Thinking ......................................... 150

Creative Thinking..................................................................... 152

Analogical Thinking.................................................................. 154

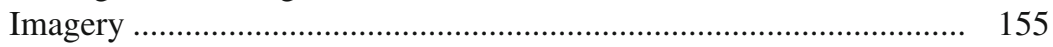

Critical Thinking ...................................................................... 156

Problem-Solving .................................................................... 156

Metacognition .............................................................................. 157

The Fallacy of 'Machine Code' ............................................................ 158

The Limits of Computing Analogies for Cognition........................... 158

A Different Type of Processing System .......................................... 159

The Ghost in the Machine: Who Tunes Our Processing Networks?... 161

Emergent Systems ......................................................................... 161

Key Terms from the Mental Register................................................ 162

\section{Part III Modelling the Science Learner's Knowledge}

\section{Introduction to Part III: Knowledge in a Cognitive}

System Approach ....................................................................... 167

The Cognitive System Approach .................................................... 168

Linking Back to the Mental Register ............................................. 170

Seeking to Understand 'Knowledge' Within the Cognitive

System Approach ....................................................................... 170

9 The Nature of the Learner's Knowledge....................................... 173

Knowledge as a Problematic Notion................................................... 173

Public and Personal Knowledge...................................................... 173

What Does It Mean to Know?........................................................... 174

Knowledge as True Reasoned Belief ........................................... 174

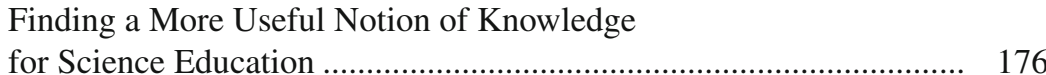

Use of the Term 'Knowledge' in Science Education ........................ 179 
Personal Knowledge.

What Are the Cognitive Resources That Support Learning?.

The Possibility of Distributed Knowledge ........................................... 183

10 Relating the Learner's Knowledge to Public Knowledge................... 191

The Notion of the Independent Reference Standard .......................... 193

Scientific Knowledge as Public Knowledge ........................................... 193

A Taken-for-Granted Notion of Scientific

Knowledge as Public Knowledge.................................................... 194

Evolving Notions of Scientific Knowledge...................................... 198

The Problem of Reifying Scientific Knowledge ............................... 199

The Analogy Between Science and the Individual .......................... 201

Target Knowledge in School and College Science ................................ 206

An Alternative, Idealist Notion of Public Knowledge ........................ 207

\section{Components of Personal Knowledge: Characterising}

the Learner's Conceptual Resources.................................................... 209

Who Ordered That? An Analogy with Particle Physics.................... 209

Finding Order in the Mental Zoo: Classifying

the Cognitivist's Collection ........................................................... 210

Key Distinctions............................................................................ 211

Terms Excluded as Not Representing Knowledge Elements ............. 211

Concepts as Knowledge .................................................................... 212

Two Types of Conceptual Knowledge ............................................ 213

Implicit and Explicit Knowledge Elements ................................... 213

The Notion of Intuitive Theories..................................................... 214

Personal Constructs ....................................................................... 215

Phenomenological Primitives............................................................ 216

Intuitive Rules ........................................................................ 217

P-Prims and Gestalts ................................................................... 218

Explicit Knowledge........................................................................ 218

Propositional Knowledge Elements ................................................ 220

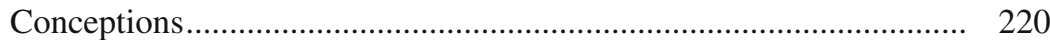

Schemata ......................................................................... 222

Visual Representations in Cognitive Structure................................ 224

Imagery as a Form of Knowledge .............................................. 224

Mental Models ............................................................................... 225

A Model of the Ontology of Knowledge in Cognitive Structure............. 226

Conceptual Frameworks and Common Alternative Conceptions ....... 228

12 The Structure of the Learner's Knowledge ..................................... 231

The Nature of a Conception ............................................................. 232

Modelling Student Conceptions with Concept Maps....................... 233

Limitations of Concept Maps as Models

of Student Conceptions ...................................................................... 235

The Importance of Conceptual Integration ......................................... 237 
The Significance of Conceptual Integration

and Coherence in Science

Conceptual Integration as a Demarcation Criterion

for Science Education

Degrees of Integration of Students' Science Knowledge ....................... 239

An Example from Learning About Atoms........................................ 239

An Example of Relating Science to Belief ...................................... 241

Discussions of Integration and Coherence

in Students' Science Knowledge.................................................... 241

Integration Across Science Topics ................................................. 245

Domain-Based Learning .................................................................. 247

Domains of Knowledge............................................................... 248

Viable Domains in Cognition....................................................... 249

\section{Part IV Modelling Development and Learning}

13 Introduction to Part IV: Development and Learning ..................... 253

Thinking of Development as Under Genetic Control ...................... 255

Thinking of Learning as Learning Environmentally Contingent........ 255

14 Models of Cognitive Development ................................................. 257

Piaget's Stage Theory of Cognitive Development ................................. 257

A Constructivist Model of Cognitive Development........................ 261

Relevance of Piaget's Theory.......................................................... 261

Piaget's Theory and Models of the Cognitive System ...................... 262

Beyond Formal Operations ................................................................. 263

Perry's Model of Intellectual and Ethical Development....................... 264

Perry's Model of Development and Models

of Cognitive Processing .................................................................... 266

Other Studies .............................................................................. 266

Social Processes in Cognitive Development........................................... 268

Modelling the Development of the Cognitive Apparatus ...................... 268

Domains of Cognition and Modularity of Mind .................................. 269

To What Extent Are Our Minds Modular?........................................ 270

Are There Inherent Domains of Knowledge? ................................... 271

Demetriou's Model of the Mind.................................................... 271

Reflecting on the Demetriou Model................................................ 273

Domains of Cognition.................................................................... 274

Folk Physics ................................................................................ 274

Folk Biology ......................................................................... 275

Development of Domains........................................................ 276

15 Modelling Conceptual Learning ................................................ 277

Is There a Learning Paradox? ............................................................. 278

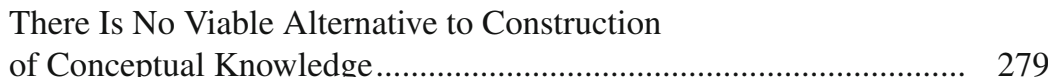


Emergence Is a Widespread Phenomenon ....................................... 280

The Task of Modelling Learning......................................................... 283

Concepts and Conceptions (Revisited) .............................................. 283

Concept Formation: Developing Spontaneous Concepts....................... 284

Introspection on Spontaneous Concepts .......................................... 285

Forming 'Reflective' Concepts ...................................................... 285

Acquiring Academic Concepts ............................................................. 286

Learning by Rote? ....................................................................... 286

Conceptual Growth: Subsuming Learning

Under Existing Conceptual Structures ........................................... 287

Learning 'Academic' Concepts......................................................... 288

Academic Concept Formation........................................................... 288

Concept Modification....................................................................... 289

Vygotsky's Notion of Concept Development ................................... 291

Melded Concepts............................................................................... 293

A Hypothetical Example of Concept Development.............................. 295

The Challenge of the Separate Domains Model

to Conceptual Development..................................................................... 301

Multiple Conceptions or Manifold Conceptions.............................. 303

Multifaceted Conceptions in Science and Science Learning ............. 306

Revolutionary and Evolutionary Conceptual Change ........................... 310

When Is Revolutionary Change Required?....................................... 313

The Notion of Conceptual Ecology ...................................................... 314

Limitations of the Conceptual Ecology Metaphor ............................ 315

Components of a Conceptual Ecology ............................................... 318

Worldviews, Scientific Attitudes and Religious Beliefs ................... 319

Student Worldviews Inconsistent with Science Learning .................. 321

Worldview as Conceptual Habitat.................................................... 322

\section{Part V Conclusion}

16 Implications for Research …......................................................... 327

Challenges for Research .................................................................... 329

The Challenge of the Persuasiveness of the Mental Register ............ 329

The Challenge of the Dynamic Nature of Memory .......................... 331

The Challenge of the Limited Purview of Consciousness ................. 333

The Challenge of Identifying Public Knowledge.............................. 334

The Challenge of the Uncertain Nature of Personal Knowledge ........ 334

The Challenge of Conceptual Development .................................... 335

The Challenge of the Idiosyncratic Nature of Cognition ................... 336

The Challenge of Sociocultural Perspectives on Learning ................ 337

Appendix ........................................................................................... 341

Testing the Logic of Research......................................................... 341

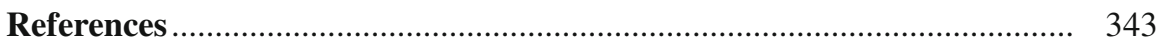

